\title{
Referências socioculturais nos Sistemas de Organização do Conhecimento
}

\section{Sociocultural references in Knowledge Organization Systems}

\author{
Marilda Lopes Ginez de Lara | USP | larama@usp.br \\ Luciana Corts Mendes | USP | luciana.corts.mendes@usp.br
}

Resumo: Os Sistemas de Organização do Conhecimento (SOC) têm suas referências ancoradas nas formas de organizar $O$ mundo enquanto representações socioculturais. Compreender como se vinculam os 'modos de organização do conhecimento aos modos de organização cultural' pode permitir verificar porque os SOC são tão diversos, porque sua validade não é universal e porque podem refletir visões de mundo privilegiadas. Concepções hegemônicas da relação entre formas socioculturais e a Organização do Conhecimento (OC) podem ter levado a que essa relação não tenha sido criticamente analisada, ficando implícita ou sendo considerada natural. Considerando essa situação, este trabalho procura discutir os padrões socioculturais tomados como referência na OC, descrever brevemente princípios relativos às concepções moderna e pós-moderna da ciência, exploraras reflexões de alguns pesquisadores da área de Ciência da Informação (Cl) sobre a relação entre o conhecimento e a $\mathrm{OC}$ e identificar algumas das implicações dessas concepções nos procedimentos e produtos da OC.

Palavras-chave: Organização do Conhecimento. Referências socioculturais. Sistemas de Organização do Conhecimento. Ciência moderna. Ciência pósmoderna.

Abstract: Knowledge Organization Systems (KOS) have their references anchored in the ways the world is organized as sociocultural references. Understanding how the processes of knowledge organization are tied to the processes of cultural organization can be the means to verify why KOS are so diverse, why their validity is not universal, and why they can mirror privileged world views. Hegemonic conceptions of the relationship between sociocultural forms and Knowledge Organization (KO) may have led to a lack of critical analysis of said relationship, which remained implicit or was considered natural. Considering this situation, this work seeks to discuss the sociocultural patterns that are taken as reference in $\mathrm{KO}$, to briefly describe principles that are related to the modern and postmodern conceptions of science, to explore the reflections of a few Information Science (IS) researchers regarding the relation between knowledge and $\mathrm{KO}$, and to identify a few of the implications of these conceptions in the procedures and products of $\mathrm{KO}$.

Keywords: Knowledge Organization. Sociocultural references. Knowledge Organization Systems. Modern science. Postmodern science. 


\section{Introdução}

Os padrões dos Sistemas de Organização do Conhecimento (SOC) não surgem num vazio, mas estão intimamente relacionados às formas de organizar o mundo que são, sobretudo, culturais. Compreender como se vinculam os 'modos de organização do conhecimento aos modos de organização cultural' pode ser o meio para verificar porque eles são tão diversos e porque sua validade não tem alcance universal. Diferentes referências culturais respondem pelas dificuldades de aplicação de uma classificação universal, ao mesmo tempo que podem refletir visões de mundo privilegiadas.

Embora essa relação entre a organização do conhecimento e a cultura sempre tenha existido, por força de concepções hegemônicas, pode não ter sido considerada criticamente. A percepção de sua influência na literatura da Ciência da Informação $(\mathrm{Cl})$ e na vida profissional pode ter ficado implícita e dada como normal. Por exemplo, o conceito de educação iluminista de 'transmissão da informação' postulou o ensino dirigido e bases universais de referência (CERTEAU, 1998), o que se refletiu nas formas de organização de determinados sistemas de classificação bibliográfica. Apesar disso, o conceito de 'transmissão da informação' ainda é utilizado sem que se reflita criticamente sobre o seu significado. Hoje, esses ocultamentos tornam-se mais patentes, o que pode ser creditado em grande parte às tecnologias de comunicação e informação: pessoas, comunidades e instituições se aproximam pelo uso da internet, aumentando a oportunidade da palavra e da manifestação das diferenças. Por sua vez, a globalização e a desterritorialização mostram que as referências culturais, embora diferentes, tendem a tornar-se homogeneizadas. Não são desprezíveis as consequências perversas dessas influências sempre que tais diferenças são ignoradas e que os padrões dominantes são reforçados e disseminados. De forma mais evidente do que no uso de determinados SOC, é o que vem ocorrendo com a língua, com os costumes, com as opiniões políticas e etc. promovida pela televisão (GARCíA CANCLINI, 2009). Apesar de menos visíveis, as relações entre organização do conhecimento e referências culturais também marcam as formas de representação em sistemas informacionais. 
Neste trabalho, nos propomos, primeiramente, a realizar uma discussão geral sobre o tema descrevendo brevemente princípios relativos às concepções moderna e pós-moderna da ciência e, em seguida, explorar o pensamento de alguns pesquisadores da área de $\mathrm{Cl}$ sobre o modo como eles relacionam as reflexões sobre o conhecimento à Organização do Conhecimento (OC). Pretendemos, também, identificar implicações dessas concepções nos procedimentos e produtos da OC e repertoriar algumas das reflexões contemporâneas sobre eles.

\section{Organização do conhecimento e referências socioculturais}

O parâmetro tradicional da OC - a partir do conceito moderno de ciência é o da racionalidade: dividir o 'real', classificá-lo, e identificar as relações entre os termos utilizados para nomear as segmentações produzidas, com base na procura por uma causalidade formal (SANTOS, 2010). Essa divisão parte, necessariamente de uma definição que, por ser fruto de uma escolha, não permite abrigar obrigatoriamente todas as variações do entendimento de um conceito. Outro modo de dizer que a divisão do real tem como ponto de partida um entendimento particular, um ponto de vista, implicando uma derivação que só é válida e aplicável dentro do mesmo sistema de referência.

Ao longo do século $X X$, o paradigma científico moderno, fundado na racionalidade científica e no cientificismo, começa a ser questionado no próprio seio da ciência. Reconhece-se que os limites e insuficiências estruturais desse paradigma resultam “do grande avanço no conhecimento que ele propiciou”, ou seja, "o aprofundamento do conhecimento permitiu ver a fragilidade dos pilares em que [ele] se fund[ou]" (SANTOS, 2010, p. 24). Ademais, os usos e desusos da ciência na sociedade, notadamente durante a Segunda Guerra Mundial - a bomba atômica, por exemplo - levaram a que o conceito de ciência, sua racionalidade e o próprio conceito de conhecimento fossem repensados. Nesse contexto cresceu o interesse pelas dimensões sociais da ciência e se tornou progressivamente mais difícil considerar apenas os aspectos ditos internos e lógicos do conhecimento científico. 
A atividade científica não é neutra e, como observa Santos (2010), a produção da ciência não é imune às interferências do observador. Se as visões produzidas pelo modelo moderno de ciência pressupunham a possibilidade de separar sujeito e objeto, partindo do pressuposto de que essa separação garantiria o afastamento necessário para a observação, o modelo pós-moderno de ciência mostra a impossibilidade dessa separação. Novas reflexões sugerem a necessidade de aceitar a lógica da auto-organização em situações de não-equilíbrio, a imprevisibilidade, a interpenetração entre propostas, a espontaneidade, a irreversibilidade, a negatividade, a desordem, a criatividade e as interferências acidentais ou conjunturais no processo de conhecimento que, enfim, questionam o modo tradicional de fazer ciência e a suposição de que ela seria a forma privilegiada de ver o mundo.

Como afirma Santos (2010, p. 37), "sendo uma revolução científica que ocorre numa sociedade ela própria revolucionada pela ciência, o paradigma a emergir dela não pode ser apenas um paradigma científico (o paradigma de um conhecimento prudente), tem de ser também um paradigma social (o paradigma de uma vida decente)", isto é, o "paradigma de um conhecimento prudente para uma vida decente". Essa perspectiva reinsere o sujeito $e$ a subjetividade no conhecimento científico, "ensina[ndo] a viver e traduz[indo]-se num saber prático" (2010, p. 55). O conhecimento passa a ser encarado necessariamente como autoconhecimento, pois "o desenvolvimento tecnológico deve traduzir-se em sabedoria de vida” (2010, p. 57). E como observam Smit e Tálamo (2007, p. 34), "o conhecimento é o modo de inserção no mundo". O sujeito faz parte do mundo e a reflexão sobre o mundo não se faz fora dele, nem se dá a partir de uma matriz neutra (RORTY, 1988), descontextualizada. Não é possível conceber o conhecimento do sujeito fora de sua inserção no mundo. Santos (2010) resume a questão propondo reconhecer que "todo conhecimento científico-natural é científico-social", que "todo o conhecimento é local e total", que "todo conhecimento é autoconhecimento", e que "todo conhecimento científico visa constituir-se num novo senso comum". 
As alterações que ocorrem na ciência se refletem necessariamente nas propostas de organização do conhecimento e em sua análise. Torna-se mais claro que procedimentos e propostas de organização do conhecimento partem de hipóteses sobre a organização do mundo e constituem, assim, probabilidades, nunca verdades. Cabe pesquisar que repercussões a história, os contextos sociais e culturais têm deixado nas metodologias de representação e de elaboração de SOC no âmbito da $\mathrm{Cl}$.

\section{Práticas socioculturais e Organização do Conhecimento}

Segundo Capurro (1986, 1999, 2003), que se baseia em filósofos e sociólogos como Heidegger e Luhmann, o conhecimento é sempre tentativo: refere-se a horizontes limitados de pré-entendimento e a comunidades que compartilham esse pré-entendimento. O observador é intérprete no interior de determinadas comunidades discursivas e estas dão suporte às seleções de sentido (informação) frente a ofertas de sentido (mensagem).

Um outro modo de compreender o conceito de pré-entendimento é relacioná-lo ao que Peirce (1974) denomina experiência colateral, que corresponde à experiência prévia ou experiência de fundo numa dimensão que ultrapassa a experiência individual e diz respeito àquela do sujeito social pertencente a uma determinada comunidade discursiva e relacionada a um domínio do saber ou área de atividade (LARA, 2007a).A significação e a interpretação, assim,se relacionam aos discursos de domínios ou áreas de especialidade que dizem respeito a universos simbólicos expressos em terminologia.

Para a $\mathrm{Cl}$, o modelo pragmático de compartilhar conhecimento é a informação, ou seja, o resultado de uma articulação de um entendimento pragmático prévio sobre um mundo comum compartilhado apresentado sob determinada forma. O pré-entendimento ancora-se nas práticas sociais e culturais que, registrado em discurso, é identificado e referenciado pela $\mathrm{Cl}$. É a partir desse entendimento que os domínios tratados pela $\mathrm{Cl}$ respondem à experiência da 
complexidade do mundo. Enquanto domínio de práticas e de conhecimento, a $\mathrm{Cl}$ responde, do mesmo modo, pela forma como define suas próprias práticas.

Para Day (2001, p. 12-13), “as histórias do livro e da informação não são contínuas e tampouco são descontínuas uma em relação à outra; em vez disto elas formam uma linha de significado histórico que molda uma tradição de cultura de informação". Ou seja, o fenômeno informação deve ser considerado em suas complexidades materiais, práticas e sociais e suas inter-relações (DAY, 2001, 2014).

Frohmann (1995, online) alinha-se a Day quando descreve aquilo que nomeia 'regime de informação': “qualquer sistema ou rede relativamente estável no qual a informação flui através de canais determináveis”, canais com "formas e estruturas específicas". Frohmann considera que regimes de informação são complexos, construídos e desconstruídos diariamente por práticas sociais interativas que não podem ser reduzidas a um único domínio, seja ele natural, social ou discursivo. Todas estas esferas são significativas em um regime de informação, todas estão inter-relacionadas, de modo que um regime de informação é entendido como uma rede de elementos heterogêneos sujeitos a práticas sociais complexas e a tensões entre grupos, interesses, discursos e artefatos científicos e tecnológicos.

Apesar de não fazer uso da expressão cultura de informação e tampouco da expressão regime de informação, Hjørland (2000, 2002) trabalha com uma concepção semelhante, afirmando que comunidades são dotadas de práticas e ideologias que correspondem a sistemas simbólicos, sistemas estes que levam à produção de registros de informação - também chamados documentos -, que são constituídos por forma, conteúdo e uso específicos. Práticas, ideologias e sistemas simbólicos também influenciam como esses documentos são interpretados individual e coletivamente e como sistemas de organização e recuperação da informação são idealizados e administrados. A informação não é o pensamento puro, uma abstração pura que passa de uma mente para a outra e é indiferente a influências materiais, institucionais e sociais, sendo o mesmo o caso dos registros materiais de informação, os documentos. "Um documento se torna informativo somente dados certos tipos de práticas documentárias" (p. 397). 
Tais práticas, enquanto ações humanas relacionadas aos documentos, são dependentes de sua materialidade, contextos de produção e uso, institucionalização, historicidade e disciplina social, uma vez que práticas documentárias requerem treinamento, ensino, correção e outras medidas disciplinares. Esse conjunto de fatores é o que determina a 'informatividade' de um documento, ou seja, aquilo que o transforma em informação, aquilo que o torna informativo. A informação emerge como um efeito de práticas documentárias institucionalizadas que, em vez de simplesmente transportarem a informação, constituem-na (FROHMANN, 2004).

De modo semelhante, Hjørland (2000, 2002, 2007) considera que documentos são contextuais, servem a funções e interesses específicos, têm uma história, um ou mais autores ou produtores e uma conexão com outros documentos. O comportamento daqueles que buscam informação deve ser, para ele, estudado em relação aos tipos de documentos, instituições de memória, áreas de conhecimento e problemas existentes. Aquele que busca informação está inserido em um contexto cultural específico, assim como suas necessidades informacionais, os documentos existentes e as instituições de memória que os albergam. Todos estão submetidos às mesmas forças produtoras de significado.

Os conceitos anteriormente discutidos - pré-entendimento, cultura de informação e regime de informação - se assemelham e se articulam em razão da importância atribuída ao compartilhamento de um modo de se situar num determinado tempo, o espírito de um tempo, como uma expressão derivada de um conjunto de fatores que respondem por um contexto histórico-filosófico e sociocultural específico. É por esse motivo que é possível identificá-los nos SOC, já que eles registram, sintetizam e refletem as expressões do que entendem como as categorias sociais e culturais de seu tempo, das quais derivam práticas e procedimentos para com a informação.

\section{Indicadores socioculturais na Organização do Conhecimento}


No domínio da OC, em seu sentido específico (HJØRLAND, 2008), os indicadores socioculturais se tornam mais perceptíveis a partir da identificação dos princípios, procedimentos e produtos das atividades de organização: classificação, indexação e os próprios sistemas de organização do conhecimento materializam as escolhas adotadas.

Para Mai (2004), os procedimentos de OC passaram de uma tradição científica onde objetivavam replicar uma realidade objetiva, para uma tradição centrada no usuário onde objetivam auxiliar nas atividades de um domínio particular do conhecimento e facilitar a comunicação entre documentos, classificadores e usuários. Para o autor (2011), a modernidade influenciou o domínio da OC com a criação de três princípios praticamente universais que guiaram a maior parte do pensamento e prática do domínio:

[...] dualismo (ao separar o conteúdo informacional do leitor), destradicionalização (ao assumir que documentos podem ser representados independentemente das atividades envolvidas em sua produção e uso), e globalização (ao assumir que documentos podem ser representados independentemente do tempo e do espaço) (MAl, 2011, p. 718).

Embora o pensamento pós-moderno, principalmente a partir dos anos 1970 levante questões relativas à interpretação dos fenômenos e questione a busca de uma meta-narrativa, para Mai (2011), diferentemente de outros domínios, a OC ainda se fundamenta fortemente nas ideias modernas.

Podemos verificar a validade das observações de Mai ao analisarmos os procedimentos e produtos da OC.

Os procedimentos de Análise Documentária ou Indexação são, em grande parte, baseados na análise e síntese. Essa referência, herdada das propostas cartesianas de redução da complexidade, continua pautando as metodologias de condensação de textos que integram sistemas informacionais específicos para produzir espécies de substitutos dos documentos. O volume crescente de informações e os problemas semânticos derivados das buscas realizadas por agentes automáticos justificam o procedimento, já que uma cartografia em tamanho natural não seria produtiva! Mas é prudente lembrar que o princípio básico da 
análise/síntese reside na ambição e na crença do poder da ciência de dominar o mundo, de controlá-lo e manipulá-lo a partir da redução de sua complexidade.

Mais do que na condensação, entretanto, é na representação do documento por meio de SOC que as referências culturais ficam mais evidentes. Primeiro, a representação de um documento individual se dá pela generalização, ou seja, procede a partir do apagamento das diferenças: não se representa o documento, mas a classe a que ele pertence. Segundo, o documento é classificado ou indexado, conforme o caso, por meio de operações de encaixe: faz-se 'coincidir' a representação do texto individual, com o termo (descritor, notação, cabeçalho de assunto e etc.) de uma linguagem documentária, cuja rede semântica organiza, sob vértices, o universo focalizado. Ao se proceder dessa maneira, aceita-se a definição que orienta o encadeamento hierárquico de termos do SOC escolhido. Os documentos classificados ou indexados por esses instrumentos ficam, assim, representados a partir das escolhas por eles operadas.

Os SOC, por seu turno, refletem suas referências transformando-as em princípios orientadores das hierarquias. Quanto mais o sistema apresenta uma organização vertical (hierárquica), mais ele determinará as formas pelas quais vão se configurar as representações. Nos sistemas de classificação bibliográfica enciclopédicos - a Classificação Decimal de Dewey (CDD) e a Classificação Decimal Universal (CDU), por exemplo - os vértices são representados pelas dez classes que se subdividem sucessivamente. A Colon Classification (CC), em relação aos sistemas anteriores, é mais flexível, não só porque tem um maior número de classes, mas porque os princípios de divisão adotados se orientam por facetas. As subordinações sucessivas são semelhantes às da CDD e CDU (hierárquicas) a não ser pelas quebras viabilizadas pela facetação.

Recursos de combinação entre itens representam a possibilidade de associações não lineares, à semelhança de um processo de sintagmatização, o que teoricamente permitiria conferir à linguagem controlada uma maior proximidade do funcionamento da linguagem natural e, portanto, maior liberdade de combinações. A comparação das possibilidades de síntese oferecidas pelos três 
sistemas mostra que, enquanto a CDD fixa as combinações autorizadas, a CDU utiliza, além de outros sinais de síntese, os dois pontos (:), recurso que autoriza a combinação entre notações dentro e fora das classes; a CC usa uma fórmula de faceta que enuncia uma síntese dentro da classe ou entre classes, e recorre a letras para identificar outros tipos de relação mais livre entre as suas unidades (os isolados). De um modo geral, esses recursos flexibilizam os sistemas (por esta razão identificados como analítico-sintéticos), mas o limite dessa flexibilização continua sendo orientado pelos vértices do sistema (as classes).

Os tesauros constituem sistemas de organização do conhecimento cujo fundamento principal são as associações horizontais (associações que se desenvolvem no eixo sintagmático, o eixo das combinações). Estas teoricamente potencializariam o desenvolvimento do 'discurso' documentário à medida que permitiriam uma combinação mais livre entre os descritores. No entanto, o alicerce dos tesauros continua sendo a hierarquia (o eixo paradigmático, ou eixo das escolhas): os planos de classificação, a seu modo, categorizam os descritores subsumindo-os em seus vértices. As sínteses entre seus descritores que, aparentemente, poderiam fugir às restrições da hierarquia, não são livremente propostas porque limitadas ao uso dos operadores booleanos (and, or, not). Além disso, como observou García Gutiérrez (1998, p. 32),

Os tesauros, apesar de haverem sido concebidos como instrumentos de vocação sintagmática, também tendem a relegar o eixo enunciativo ao plano das dependências e das substituições. Por esse motivo, observamos que a maioria das microestruturas alimentadas por operadores TR (...) pertence ao eixo paradigmático do mesmo modo que os operadores de equivalências (USE/UP) e hierarquia (TG/TE).

A função paradigmática, portanto, acaba eclipsando a função sintagmática (GARCÍA GUTIERREZ, 1998). Outro modo de dizer que a lógica que orienta os tesauros é definida pela hierarquia. A lógica que orienta a construção dos tesauros continua sendo a lógica da dedução e do encaixe.

A norma de construção de tesauros, a ISO 25964 (2011; 2013), não altera a lógica anterior continuando a conferir ênfase à hierarquia e ao princípio da mútua exclusividade, muito embora alguns recursos representam uma iniciativa em direção 
à flexibilização, como é o caso do tratamento das equivalências entre termos. A norma é a mesma para os contextos mono e multilíngues e, por essa razão, trata com maior profundidade as relações de equivalência entre os termos não só permitindo acolher diferenças, como ausências quando se trata de uma ou mais línguas. Outro recurso é a motivação de promover a interoperabilidade entre vocabulários (de diferentes tipos, como sistemas de classificação, listas de cabeçalho de assunto, tesauros etc.), começando pelo mapeamento, um meio de comparar diferentes vocabulários para, em seguida, propor equivalências entre seus termos. Nesse contexto, a norma abre a possibilidade de trabalhar com estruturas não simétricas, acolhendo tesauros multilíngues e multiculturais. Além dos mapeamentos entre vocabulários que compartilham a mesma estrutura hierárquica e associativa (por exemplo, mapeamento do mesmo instrumento em duas línguas), é possível, ao menos teoricamente, comparar vocabulários que não têm a mesma estrutura, bem como tomar um vocabulário central como referência para realizar as comparações.

Em resumo, pode-se afirmar que há um relativo esforço dos agentes da OC em direção à flexibilização, mas ela ainda é fundamentalmente baseada no ideário da modernidade.

\section{Reflexões contemporâneas sobre Organização do Conhecimento}

Nos dias de hoje, muitos dos pesquisadores da $\mathrm{OC}$ se mostram críticos às teorias que pretendem postular uma linguagem universal e, consequentemente, classificações universalmente aplicáveis. É visão corrente que as classificações são construções provisórias e de validade espaço-temporal específicas, corroborando a afirmação de Borges (1952, online) de que "não há classificação que não seja arbitrária e conjectural”.

“Classificar tem, entre suas muitas acepções, uma aparência perversa e paradoxal: ocultar conhecimento. Seu contrário, a desclassificação, significaria, consequentemente, sua exposição” (GARCÍA GUTIÉRREZ, 2006, p. 110). Em sua proposta de uma epistemografia prática, García Guitérrez propõe desclassificar, 
desconstruir, desmontar, criticando a classificação hegemônica para, em seu lugar, tornar presente conhecimentos e culturas marginais. Para o autor, isso requer buscar outras lógicas que permitam uma configuração horizontal, interativa e transdisciplinar. Um exemplo seria recorrer à lógica paraconsistente, de Newton da Costa, por meio da qual é possível admitir a contradição, simultaneamente, A e não A. Ou então utilizar o pluralismo lógico como meio de contemplar o conhecimento submerso, situado.

Sem se referir diretamente aos conceitos de cultura de informação e regime de informação, discutidos anteriormente, García Gutiérrez (2018)faz uma análise do que poderíamos identificar como um amplo regime de informação - o ocidental, caracterizado pela racionalidade. Para o autor, a racionalidade não só se opõe à crença, mas é, exatamente, uma crença a mais. É em sua crítica ao conceito de racionalidade que Gutiérrez propõe a desclassificação, procedimento que implicaria em intervir estrategicamente nas fontes de raciocínio de modo a denunciar o pensamento binário e abraçar a contradição para mostrar que a razão é, mais do que qualquer outra coisa, uma modalidade de fé. A desclassificação seria um modo de exercer uma fé desconfiada. Trata-se de crer na mudança, em uma estabilidade que é instável e pode mudar em seguida. Uma perspectiva desclassificada situa-se em uma hermenêutica de suspeita, foge à enfermidade da racionalização, “patologia catalogada por Edgar Morin” (1996, citado por GARCÍA GUTIÉRREZ, 2018, p.46). Na ótica da desclassificação, a razão "trabalharia a serviço de instintos, pulsões e emoções (e não o contrário)" (2018, p.47).

Gutierrez destaca o fato de que nossa percepção do mundo é marcada pela classificação de suas representações, pela mediação e medição lógica, categorial da classificação. Referindo-se à língua tojolabal, do México, mostra a diferença cultural entre os povos quando compara o que organizamos como 'parte' ao que essa língua trata como 'pedaço'. O tojolabal vê pedaços onde os ocidentais vemos partes, e o que vemos como legalmente dividido, asséptico, eles consideram fraturado, quebrado.

O autor questiona a existência de uma verdade única, afirmando que 
$\mathrm{Na}$ era da transcultural digital, a verdade se reduzirá, de fato, à interação de valores, a uma verdade como processo, como trânsito, como precariedade, como impostura, como pós-verdade (GARCíA GUTIÉRREZ, 2018, p.56).

A realidade é irrepresentável em razão de nossas limitações cognitivas. O conhecimento seria um conjunto de conceitos isentos, de fragmentos interconectados frente à incapacidade de aceder ao real. A realidade não é uma mera construção subjetiva.

Sob outra chave, Olson explora o problema de classificar pelas essências, tal como muitas propostas de OC. Reportando-se às origens da classificação, a autora observa que a base da maioria dos SOC é o silogismo aristotélico, aparentemente universal. Dessa aparência, teriam sido derivados os princípios da mútua exclusividade, a teleologia e a hierarquia. Olson mostra, no entanto, que ao definir um universo, automaticamente se define seus limites. “A classificação é um sistema e sistemas têm limites que excluem, pois eles são como territórios finitos" (OLSON, 2002, p. 382). Para a autora, podemos buscar respostas mais adequadas a partir da sobreposição de sistemas e da identificação de objetos fronteiriços, um meio de atender a diferentes comunidades de prática. Um exemplo seria buscar conectar vários tipos de vocabulários a partir de seus múltiplos significantes considerando significados comuns, sem privilegiar um vocabulário central ou um vocabulário em detrimento de outros, procurando estabelecer relacionamentos quase-hierárquicos.

Se pensamos na classificação como algo que potencialmente aumenta o significado, podemos ultrapassar as limitações da mútua exclusividade lançando mão de sobreposições nos pontos de fronteiras (OLSON, 2002, p. 389).

Na proposta de Mazzocchi (2013), cujo projeto enfatiza a necessidade de nos livrarmos das estruturas dominantes e paralisantes (e de essências, segundo outros autores), ao modelo de árvore, imagem da lógica clássica que presidiu a organização dos modelos de classificação, pode-se opor o mapa, o labirinto e a rede. Para ele, o rizoma, proposto por Deleuze e Guattari, pode ser considerado o símbolo do período pós-moderno que permite enfatizar a natureza contingente do conhecimento. Em discussão sobre o modelo da enciclopédia semiótica (LARA, 1999), ressalta-se o fato de que o rizoma proposto por Deleuze \& Guattari é uma 
rede de árvores abertas a todas as direções, o que para Eco (1991) confirmaria a inconsistência da árvore de Porfírio, ao mesmo tempo em que se configuraria como uma descrição provisória para dar conta de porções à enciclopédia. A utilização do rizoma, no entanto, ainda estaria limitada ao uso simultâneo de inúmeras hierarquias.

López-Huertas (2013), por seu turno, propõe buscar novas lógicas para escapar às restrições impostas pelas dicotomias. Reconhecendo as alterações epistemológicas experimentadas no momento presente, a autora sugere considerar o modelo de transdisciplinaridade de Nicolescu e as teorias de García Gutiérrez (aqui referidas anteriormente). Elas permitiriam prover os sistemas de maior abertura e porosidade, fazendo um contraponto aos limites impostos pelas estruturas de organização do conhecimento sob a forma de árvore, além de permitir organizar categorias e conceitos em sistemas transversais.

Francelin (2010) chama a atenção para o fato de que grande parte dos artigos brasileiros sobre Organização da Informação e do Conhecimento (OIC), seguindo a terminologia do autor, tem como base a Teoria analítica do conceito, a teoria da classificação facetada, a Teoria Geral da Terminologia, e as propostas de Ontologias. As referências teóricas dessas abordagens recorrem a "autores como Dahlberg, Ranganathan, Wüster e Guarino” (2010, p. 180), cujas

\footnotetext{
linhas de força teórica ... estão calcadas, fundamentalmente, na lógica aristotélica, melhor representada pelas categorias, e pelo princípio de fixação da linguagem ou conceito por meio de juízos e proposições verdadeiras, características básicas da filosofia analítica e do positivismo lógico (p. 180).
}

Abordagem inovadora sobre a Teoria do Conceito é a de Derqui (2017), para quem a própria definição de conceito já implicaria uma definição específica de informação. Derqui propõe não separar a compreensão do fenômeno informação da formação mesma do conceito, considerando-os interdependentes. $O$ autor sugere verificar como eles se comportam nos domínios cognitivo, social e comunicacional. Ele questiona a concepção cognitivista tradicional que separa sujeito e objeto no ato de conhecimento, característica do modelo racionalista de 
ciência, e propõe ver a representação como mediação e como formadora da cognição, necessariamente articuladas às esferas social e cultural.

Derqui adota uma abordagem sistêmica da teoria do conceito e recorre a Maturana, Varela e Luhmann, entre outros, para discutir a questão da informação e do conhecimento, considerando conceitos como os de complexidade, autoorganização e dando destaque à alteração do papel do observador da teoria clássica. Para o autor, os conceitos emergem de complexos emaranhados de informação, primeiramente por expansão, ou ampliação de sua esfera de aplicação e, em seguida, por redução quando, fora de seu contexto original, tornam-se generalizáveis (DERQUI, 2017). Trata-se de uma visão polêmica, mas importante de ser considerada pelas influências que pode ter no domínio da $\mathrm{Cl}$ e da OC.

\section{Conclusão}

A enumeração das reflexões críticas sobre os modos de tratar teoricamente as questões de OC no momento contemporâneo não se esgota nos limites deste trabalho. Abordar a questão é tão importante quanto identificar suas projeções práticas, reflexão essa que deve ser objeto de outras pesquisas.

Ao longo do texto verificamos que a ciência de um modo geral, e a Ciência da Informação, em particular, não permanecem imunes às transformações ocorridas entre o final do século $X I X$ e meados do século $X X$. Os padrões socioculturais tomados como referência para a organização do conhecimento conferiram privilégio aos parâmetros modernos de ciência, seguindo o iluminismo e suas variações. Esse parâmetro que tem como princípio a busca e o controle de uma realidade objetiva, vem aos poucos sendo substituído pelo que alguns teóricos denominam ciência pós-moderna, cuja referência primeira é a própria crítica da ciência como forma privilegiada de conhecer o mundo. Se a racionalidade buscava simplificar o real, agora temos de dar conta da complexidade do mundo.

A literatura mostra que experimentamos, hoje, um momento de transição e de convivência de referências modernas e pós-modernas. Muito embora as primeiras estejam na base dos procedimentos e produtos da $\mathrm{OC}$, há reflexão crítica 
em direção à segunda como o demonstram os trabalhos de Olson, García Gutiérrez, Mazzocchi, López-Huertas, Francelin, Derqui, entre outros, que problematizam a crença nas essências, os limites das hierarquias e da causalidade formal.

É importante verificar o esgotamento de teorias baseadas nas dicotomias clássicas cuja operacionalização, embora se mantenha suficiente para os domínios onde há consenso e estabilidade, não dá conta de forma adequada do tratamento da informação de domínios das ciências sociais e das humanidades. Importante, também, é constatar a necessidade de procurar por instrumental metodológico que faça frente, convenientemente, à possibilidade de organização híbrida, além de acolher a diversidade e a possibilidade da instabilidade conceitual.

Como afirmou Edgar Morin (2005, p. 37),

Não se trata mais de obedecer a um princípio de ordem (eliminando a desordem), de claridade (eliminando o obscuro), de distinção (eliminando as aderen̂ncias, as participações e as comunicações), de disjunção (excluindo o sujeito, a antinomia, a complexidade), ou seja, obedecer a um princípio que liga a ciência à simplificação lógica. Trata-se, ao contrário, de ligar o que estava separado através de um princípio de complexidade.

\section{Referências}

BORGES ACEVEDO, J. F. I. L. Otras inquisiciones. Buenos Aires: Sur, 1952. Disponível em: <http://languagelog.ldc.upenn.edu/myl/ldc/wilkins.html>. Acesso em: 28 maio 2017.

CAPURRO, R. Epistemologia e Ciência da Informação. In: ENCONTRO NACIONAL DE PESQUISA EM CIÊNCIA DA INFORMAÇÃO (ENANCIB), 5., 2003, Belo Horizonte.

Anais... Belo Horizonte: ANCIB, 2003. Disponível em:

<www.capurro.de/enancib_p.htm>. Acesso em: 27 maio 2017.

CAPURRO, R. Foundations of Information Science: review and perspectives.[S.I.]: [s. n.], 1999. Disponível em: <http://www.capurro.de/tampere91.htm>. Acessoem: 26 maio 2017.

CAPURRO, R.Hermeneutik der Fachinformation. Freiburg: Alber, 1986.Disponível em: <http://www.capurro.de/hermeneu.html>. Acesso em 26 maio 2017.

CERTEAU, M. A invenção do cotidiano: artes de fazer. 3 ed. Petrópolis: Vozes, 1998. DAY, R. E. The modern invention of information: discourse, history, and power. Carbondale: Southern Illinois University Press, 2001.

DAY, R. E. Indexing it all: the modern documentary subsuming of the subject and its mediation of the real. In: iCONFERENCE, 2014, Berlin. Proceedings... Urbana- Champaign: iSchools, 2014. p. 565-576. 
DERQUI, P. M. Da informação à categorização: a formação sistêmica dos conceitos. Curitiba: CRV, 2017.

FRANCELIN, M. M. A ordem dos conceitos na Organização da Informação e do Conhecimento. São Paulo: Escola de Comunicações e Artes, 2010. 220 f. (Tese de Doutorado em Ciência da Informação).

FROHMANN, B. Taking information policy beyond Information Science: applying the actor network theory. In: ANNUAL CONFERENCE OF THE CANADIAN ASSOCIATION FOR INFORMATION SCIENCE, 23., 1995, Edmonton. Electronic proceedings... Edmonton: University of Alberta, 1995. Disponívelem: https://www.ualberta.ca/dept/slis/cais/frohmann.htm >. Acessoem: 12 jun. 2015.

FROHMANN, B. Documentation Redux: Prolegomenon to (Another) Philosophy of Information. Library Trends, v. 52, n. 3, p. 387-407, 2004.

GARCÍA CANCLINI, N. Diferentes, desiguais e desconectados: mapas da interculturalidade. 3 ed. Rio de Janeiro: UFRJ, 2009.

GARCÍA GUTIÉRREZ, A. Cientificamente favelados: uma visão crítica do conhecimento a partir da epistemografia. Transinformação, v. 18, n. 2, p. 103-112, 2006.

GARCÍA GUTIÉRREZ, A. En pedazos: en sentido de la desclasificación. Madrid: Editorial ACCI, 2018.

GARCÍA GUTIÉRREZ, A. Principios de lenguaje epistemográfico: la representación del conocimiento sobre Patrimonio Histórico Andaluz. Granada: Editorial Comares, 1998.

HJØRLAND, B. Arguments for 'the bibliographical paradigm': some thoughts inspired by the new English edition of the UDC. Information Research, v. 12, n. 4, 2007. Special supplement: Proceedings of the Sixth International Conference on Conceptions of Library and Information Science - "Featuring the Future". Disponível em:

<http://www.informationr.net/ir/12-4/colis/colis06.html>. Acessoem: 14 jul. 2014.

HJØRLAND, B. Documents, memory institutions and Information Science. Journal of Documentation, v. 56, n. 1, p. 27-41, 2000.

HJØRLAND, B. Principia Informatica: foundational theory of information and principles of information services. In: INTERNATIONAL CONFERENCE ON CONCEPTIONS OF LIBRARY AND INFORMATION SCIENCE (COLIS4): EMERGING FRAMEWORKS AND METHODS, 4., 2002, Seattle. Proceedings... Greenwood Village, Colorado: Libraries Unlimited, 2002. p. 109-121. Disponível em: <http://www.iva.dk/bh/core\%20concepts\%20in\%20lis/articles\%20az/ principia_informatica.htm>. Acesso em: 06 out. 2014.

HJØRLAND, Birger. What is Knowledge Organization (KO)? Knowledge Organization, v. 35, n. 2/3, p. 86-101, 2008. 
INTERNATIONAL STANDARD ORGANIZATION. ISO 25964: thesauri and interoperability with other vocabularies. Part 1: Thesauri for information retrieval. Genebra: International Standard Organization, 2011.

INTERNATIONAL STANDARD ORGANIZATION. ISO 25964: thesauri and interoperability with other vocabularies. Part 2: Interoperabilitywithothervocabularies. Genebra: International Standard Organization, 2013.

LARA, M.L.G. A construção da informação no universo da linguagem na contemporaneidade. In: LARA, M.L.G.L.; FUJINO, A.; NORONHA, D.P. Informação e contemporaneidade: perspectivas. Recife : Néctar, 2007b, p.153-168.

LARA, M.L.G. Informação, informatividade e Linguística Documentária: paralelos com as reflexões de Hjorland e Capurro. Anais, Encontro Nacional de Pesquisa em Ciência da Informação - ENANCIB, 3, 2007a. Disponível em: http://www.enancib.ppgci.ufba.br/artigos/GT2--185.pdf

LARA, M.L.G. Representação e linguagens documentárias: bases teórico-metodológicas. São Paulo: Escola de Comunicações e Artes, 1999. 189p. (Tese de Doutorado em Ciências da Comunicação).

LÓPEZ HUERTAS, M. J. Reflexions on muldimensional knowledge: its influence on the foundation of knowledge organization. Knowledge Organization, v.40, n.6, p.400-407, 2013.

MAI, J-E. 2004. Classification of the web: challenges and Inquiries, Knowledge Organization, v. 31, n. 2, p. 92-97, 2004.

MAI, J-E. The modernity of classification. Journal of Documentation, v. 67, n. 4, p. 710730, 2011.

MAZZOCCHI, F. Images of thought and their relation to classification: the tree and the net. KnowledgeOrganization, v.40, n.6, p.366-375, 2013.

MORIN, E. O método: a natureza da natureza. Porto Alegre: Sulina, 2005.

OLSON, H. Review article: classification and universality application and construct. Semiotica, v.139, n.1/4, p.377-391, 2002.

PEIRCE, C. S. Semiótica.Trad. José Teixeira Coelho Netto; rev. J. Guinsburg. São Paulo: Perspectiva, 1974 (Estudos, n.46).

RORTY, R. A filosofia e o espelho da natureza. Lisboa: Dom Quixote, 1988.

SANTOS, B. S. Um discurso sobre as ciências. 16. ed. Porto: Afrontamento, 2010.

SMIT, J.W., TÁLAMO, M.F. Ciência da Informação: uma ciência moderna ou pósmoderna? In: LARA, M.L.G.; FUJINO, A.; NORONHA, D. P. (Org.). Informação e contemporaneidade: perspectivas. Recife: Néctar, 2007. p.27-46. Disponível 
em: <www2.eca.usp.br/nucleos/colabori/documentos/Infoeducacao.pdf> . Acesso em: 27 maio 2017. 